\title{
A interação entre estranhos no Omegle.com: sociabilidade, relacionamento e identidade
}

\author{
Alex Damasceno
}

\section{Resumo}

À luz do método proposto por Simmel, centrado no conceito de sociabilidade, investigamos neste artigo a dimensão lúdica do site de conversação Omegle. com, com o objetivo de apreender a forma das suas interações. Para isso, problematizamos as duas características diferenciais do site. Primeiramente, baseados na fenomenologia social de Schutz, discutimos a formação de relacionamentos através do uso de um sistema randômico. Em segundo lugar, fundados na dialética da identidade de Ricoeur, refletimos como o site constitui um sujeito anônimo, designado de "estranho". Como conclusão, entendemos que o jogo social praticado no Omegle se caracteriza pelo equilíbrio, dinamismo e efemeridade, sendo utilizado para os mais diferentes propósitos, como a simples conversa, o sexo virtual, a aprendizagem autônoma e a observação social.

\section{Palavras-Chave}

Interação social. Omegle. Sociabilidade.

Relacionamento. Identidade.

\section{Introdução}

0 Omegle.com é um website norte-americano criado em 2009 que, como muitos outros espalhados na internet, disponibiliza gratuitamente o serviço de chat (sala de batepapo), possibilitando o intercâmbio de mensagens sempre entre dois usuários. Contudo, ele possui duas características que, ao estarem reunidas, 0 diferenciam da maioria dos chats. A primeira é a adoção de um sistema conhecido popularmente pela expressão chatroulette, ${ }_{1}^{1}$ no qual o próprio site estabelece os pares de conversação de forma randômica: o usuário não pode, assim, escolher o seu parceiro de conversa. A segunda é a dissolução identitária do usuário, que não tem a opção de elaborar perfis ou nicknames que permitam o seu reconhecimento por outros (o serviço sequer requisita um cadastro). Por isso, o Omegle resume sua funcionalidade na seguinte frase exibida na sua página inicial: Talk to strangers (fale com estranhos).

São oferecidos no site três modos de conversação, cada um com suas diferentes dinâmicas: 0 modo
Alex Damasceno I damasceno-alex@ig.com.br Doutorando em Comunicação e Informação na Universidade Federal do Rio Grande do Sul (UFRGS). Bolsista da Coordenação de Aperfeiçoamento de Pessoal de Nível Superior (Capes). 
text, no qual os usuários trocam apenas mensagens escritas; o modo spy (question), em que um usuário faz uma pergunta (também escrita) que inicia 0 chat de outros dois e ele pode observar a conversa sem intervir nela; o modo video, no qual, além das mensagens escritas, há uma troca de sinais de imagem e som, com o uso de webcams, microfones e alto-falantes. Nos três modos, 0 usuário pode finalizar a conversa a qualquer momento, ao clicar na tecla "esc" do teclado ou em um botão da interface gráfica, sendo direcionado a um novo parceiro no intervalo de dois segundos.

A expressão "interação entre estranhos", utilizada no título do artigo para caracterizar as relações sociais estabelecidas no Omegle, é uma referência a Georg Simmel (1983, p. 173), sociólogo que formula o conceito de sociabilidade como uma "interação entre iguais", o tipo mais puro de interação, simétrico, equilibrado e lúdico. Para Simmel (1983, p. 47), o estudo das interações sociais encontra seu domínio na investigação das "formas que tomam os grupos dos homens, unidos para viver uns ao lado dos outros, ou uns para os outros, ou então uns com os outros". 0 autor aponta que as formas sociais existem por si mesmas, sendo resultantes do fenômeno da sociabilidade, e não de suas finalidades e conteúdos. A base do seu método é, portanto, uma separação entre forma e conteúdo (SIMMEL, 1983, p. 168).
Pensamos que essa separação é profícua para observação de interações fundadas na conversação, como é o caso do Omegle. Pois, de acordo com Simmel (1983), podemos iniciar uma conversa com o objetivo de entender um assunto específico, mas também nossa finalidade pode ser apenas conversar por conversar. No primeiro caso, a forma está em função da comunicação de um determinado conteúdo; no segundo, ela está "a serviço de inúmeros conteúdos e propósitos da vida humana" (SIMMEL, 1983, p. 176). É nesse segundo exemplo que a conversação adquire a dimensão lúdica da sociabilidade, pois o mais importante passa a ser o jogo compartilhado entre os sujeitos. Entendemos que as interações do Omegle devem ser observadas pelo prisma da sociabilidade, seguindo o pensamento de que os seus usuários não buscam a comunicação de um conteúdo específico, e sim são impulsionados pelo próprio prazer do jogo.

Isso não implica em dizer que os conteúdos não sejam importantes para o estudo das interações sociais. Ao observamos o Omegle durante 0 ano de 2012, percebemos que a maioria das conversas no modo video era motivada por conteúdos sexuais (nudez, masturbação, principalmente do sexo masculino). 0 site, porém, mudou suas regras de funcionamento no início de 2013: primeiramente, passou a monitorar as conversas e encaminhar os usuários que aparecem nus para um chat 
reservado para maiores de 18 anos; em segundo lugar, disponibilizou na sua página inicial links para sites especializados em videochats sexuais, acompanhados da frase Here's a free adult site, if you're after that ("Aqui está um site adulto grátis, se você está atrás disso"). Desse modo, para manter a forma do seu jogo e não correr o risco de institucionalizá-la em função de um propósito único, o próprio Omegle passou a estimular os usuários que buscavam apenas conteúdo sexual a saírem do site; considerou, assim, ser mais importante a manutenção da sua forma de interação do que manter uma determinada quantidade de acessos proporcionada por um conteúdo popular. Podemos notar, a partir desse exemplo, que a investigação de uma forma social também requer o conhecimento do seu conteúdo, uma vez que a interação é construída na relação dinâmica entre os dois. 0 que Simmel (1983) defende é que não devemos ter a matéria da vida social como objeto, e sim a sociabilidade: o movimento proposto é uma reaproximação de interações destinadas a diferentes finalidades, para que seja liberado justamente aquilo que elas têm em comum.

Dessa maneira, com o objetivo de apreender a forma das interações sociais do Omegle, voltamo-nos as duas características mencionadas anteriormente, que 0 diferenciam dos outros chats, problematizando-as numa aproximação de Simmel com pensadores afins. No primeiro tópico do artigo, discutimos a formação dos atos comunicativos e os tipos de relacionamentos gerados pelo sistema randômico, apoiados na fenomenologia social de Alfred Schutz (1979). No segundo, investigamos o processo de constituição desse sujeito designado de "estranho", com base na dialética da identidade proposta por Paul Ricoeur (1991). Por fim, voltamos a Simmel e descrevemos, a partir da reflexão sobre os dados observados nas discussões anteriores, os elementos que compõem o jogo compartilhado entre os usuários do site.

\section{0 relacionamento randômico}

De modo abrangente, já descrevemos o Omegle como um sistema que permite que dois sujeitos interajam numa conversação. Seguindo a tese sobre interatividade de Alex Primo (2000), podemos tornar essa descrição mais precisa e defini-lo como um ambiente informático de interação mútua, ao invés de uma interação meramente reativa com o computador. Como a abordagem de Primo centra a investigação no plano da mediação computacional, consideramos ser importante articular a essa definição 0 aparato conceitual da fenomenologia social de Alfred Schutz (1979), pesquisador dos relacionamentos face a face. Com essa articulação, buscamos compreender tanto a dimensão intersubjetiva do processo comunicacional (os diferentes tipos de relacionamento, os papéis desempenhados pelos sujeitos, as suas motivações e as linguagens utilizadas) como as características próprias da mediação por computador (o uso das ferramentas da web 2.0). 
Formada a partir do conceito de intersubjetividade de Edmund Husserl, a premissa do pensamento de Schutz (1979) é que um sujeito não percebe o seu semelhante como um objeto, e sim como um contrassujeito, a quem naturalmente confere vida e consciência. ${ }^{2} \mathrm{~A}$ esse fenômeno, 0 autor dá 0 nome de "orientação para 0 Tu":

Essa é uma experiência pré-predicativa, através da qual me torno consciente de um ser humano, meu semelhante, como uma pessoa. A orientação para o Tu pode então ser definida como a intencionalidade dos Atos através dos quais 0 Ego capta a existência da outra pessoa no modo do eu original. Toda experiência externa desse tipo no modo do eu original pressupõe a presença real da outra pessoa e minha percepção dela como presente (SCHUTZ, 1979, p. 181).

É a experiência que reúne a compreensão do outro como um sujeito, o compartilhamento com ele de um mesmo tempo-espaço, a possibilidade de intercomunicaçãa ${ }^{3}$ e a interpretação das motivações, intenções e pensamentos por trás dos seus atos, que Schutz (1979, p. 180) denomina de "relacionamento do Nós". Nesse sentido, um relacionamento nada mais é, para o autor, do que duas pessoas envelhecerem juntas. Entretanto, Schutz aponta que somos incapazes de apreender o relacionamento do Nós em sua forma pura, uma vez que 0 vivenciamos por dentro: não conseguimos alcançar a consciência do outro, 0 seu "estar lá" (Dasein). Ou seja, em seu estado puro, o relacionamento é um "simples conceito limitador, que se usa na tentativa de chegar a uma captação teórica da situação face a face" (SCHUTZ, 1979, p. 185). 0s relacionamentos, desse modo, devem ser observados em sua concretude, variando em relação aos pontos de vista, graus de imediatidade, intimidade, intensidade etc.

No caso do Omegle, é preciso notar, em primeiro lugar, que o sistema randômico transforma os relacionamentos em atos isolados. Eles não têm passado, uma vez que os sujeitos não possuem nenhuma informação anterior sobre o outro, 0 que dificulta a compreensão subjetiva mútua. Certamente que durante a conversa, podemos entender 0 significado objetivo das palavras que nos são dirigidas. Mas sem um relacionamento prévio, escapa-nos o que Schutz (1979, p. 183) denomina de significado subjetivo, que nos permitiria inferir sobre os pensamentos que estão por trás das palavras e habitam a consciência do outro. Os relacionamentos do Omegle também se caracterizam pela impossibilidade de futuro, à

Por mais que a consciência do outro não possa ser comprovada. Schutz (1979, p. 159) cita o caso dos behavioristas radicais que apontavam a impossibilidade de verificação da vida do outro. 0 autor rebate com uma ironia, ao dizer que esses pensadores "não poderiam encontrar-se com outros em congressos onde se prova reciprocamente que a inteligência do outro é um fato questionável". E ele completa, "na medida em que os seres humanos não são invenções, homenzinhos polêmicos, mas nascidos e criados por mães, a esfera do Nós será ingenuamente pressuposta" (SCHUTZ, 1979, p. 159).

Helmut R. Wagner, tradutor dos textos de Schutz para o português, explica em uma nota a sua opção pelo termo intercomunicação, ao invés de comunicação, para transmitir o pensamento original do autor: "0 termo intercomunicação pode soar redundante. No entanto, insistimos em seu uso de forma a indicar com clareza aquilo que Schutz queria dizer com comunicação, como uma rua de mão dupla, um intercâmbio autêntico, e não torrentes unidirecionais, como nos casos dos meios de comunicação de massa" (SCHUTZ, 1979, p. 36). 
medida que é bastante improvável que uma dupla de conversação seja repetida, embora os usuários possam trocar informações para dar continuidade à relação em outros ambientes de comunicação. Dessa forma, o relacionamento randômico também pode ser definido como envelhecer juntos, porém é um envelhecimento de um momento isolado, sem passado e futuro, restrito a um momento presente.

Com a ausência de um passado, os relacionamentos podem se caracterizar pelo reduzido grau de intimidade, já que não é comum travarmos interações íntimas com pessoas que acabamos de conhecer (e que nem sequer conhecemos pessoalmente). Por outro lado, a finitude própria do relacionamento randômico, apoiada também no anonimato (que discutiremos no tópico seguinte), faz com que boa parte das interações do Omegle seja caracterizada por um alto nível de intimidade, como nos casos em que os usuários praticam atos sexuais. Mas deve-se destacar que os estudos de cibercultura já chamaram a atenção para esse fenômeno próprio da contemporaneidade, na conclusão de que a web 2.0 reconfigura a noção de intimidade. Como aponta Paula Sibilia (2008, p. 60), vemos na atualidade um deslocamento de uma subjetividade interiorizada para uma exteriorizada. A partir dos termos "exterior" e "intimidade", a autora utiliza o trocadilho extimo (ou extimidade) para caracterizar o paradoxo do fenômeno. 0 que podemos notar no caso do Omegle é que as interações possuem variações de intimidade, que vão desde a simples conversa até o relacionamento sexual. ${ }^{4}$

Para que 0 relacionamento se efetive de forma intensa e dinâmica, Schutz (1979) conclui ser necessária uma reciprocidade de motivos: os sujeitos devem compartilhar as mesmas motivações, de maneira que a ação de um deles não encaminhe a uma reação negativa do outro, que dê fim ao relacionamento. No Omegle, a reciprocidade das motivações é um fator essencial para a formação do relacionamento, pois, como vimos, é o próprio usuário quem escolhe o momento de finalizar a conversa. Como é impossível escolher a pessoa com quem se vai conversar ou conhecer suas motivações previamente através de um perfil, os relacionamentos tendem a ser efêmeros e demora algum tempo até que se encontre um bom parceiro de conversa. Para dinamizá-los, o site passou a adotar duas ferramentas que agem em seu sistema randômico na tentativa de direcionar para um mesmo chat pessoas que tenham motivações recíprocas. A primeira delas é o commom interests, uma caixa de texto da interface na qual o usuário, antes de ser direcionado a um chat, escreve os conteúdos que ele deseja abordar. Assim, ele é direcionado a uma pessoa que tenha digitado termos referentes aos mesmos temas. 
A segunda ferramenta é ofacebook likes, que permite ao site acessar a conta do Facebook de um usuário, com a permissão dele, e cruzar seus dados com os de outros, para formar pares de conversação. Ou seja, o fato de os relacionamentos se estabelecerem de forma randômica não quer dizer que a escolha seja sempre arbitrária.

Além dos motivos, Schutz (1979, p. 199) coloca a linguagem como fator decisivo para a formação de um relacionamento. Para 0 autor, a noção de linguagem é tomada como um dado sempre a priori, ou seja, para que se constitua um ato comunicativo deve haver um compartilhamento de signos: se espera uma determinada interpretação da pessoa a quem um signo foi dirigido. Em um primeiro momento, Schutz se refere ao conjunto de regras da língua materna de uma comunidade. No caso do Omegle, um site norte-americano, até 0 ano de 2012, a língua padrão do ambiente era o inglês, o que limitava 0 acesso para usuários que falavam outros idiomas. Por outro lado, os resultados dos experimentos que Soares Silva (2011) realizou no Omegle mostram que, ao ser um ambiente dominado por um idioma, o site pode ser utilizado como uma ferramenta de apoio educacional do inglês como língua estrangeira, ao possibilitar "uma aprendizagem autônoma, onde 0 aprendiz vai em busca das significações através das interações aleatórias" (SILVA, 2011, p. 18). É evidente que essa interação educacional também depende da reciprocidade de motivações: ela é formada tanto pela vontade de aprender de um usuário como pela disponibilidade de ensinar do outro.

No início de 2013, porém, o Omegle operou outra modificação em seu sistema, que permitiu aos usuários a seleção da língua para a interação, em um universo que conta com mais de 50 idiomas. Por um lado, isso possibilitou a abertura do site para outros usuários, o que supostamente aumenta o número de acessos ${ }^{5}$. Por outro lado, a escolha da língua divide 0 universo de participantes em grupos menores, 0 que pode ocasionar repetições na formação dos pares de conversação. Na nossa experiência de navegação pelo site, ao escolhermos 0 português como o idioma da interação no modo video (que nos permite ver com quem estamos conversando), após um determinado tempo em que trocamos várias vezes nossos pares, eles começaram a se repetir. De certo modo, a escolha do idioma introduz um risco à manutenção do jogo. Esse ponto será retomado no próximo tópico, pois a argumentação está atrelada à questão do anonimato.

Após observar esse nível macro da linguagem, Schutz (1979) chama a atenção para o fato de que a própria língua pode alcançar altos níveis de formalização e ter uma significação restrita a subcomunidades. 0s usuários do Omegle, 
de fato, utilizam signos específicos relativos a codificações da escrita que são típicas da internet, algumas inclusive criadas em seu próprio ambiente. Por exemplo, boa parte das conversas em inglês é iniciada pela pergunta "asl?", uma sigla para age, sex and location? (idade, sexo e local?). Trata-se de uma pergunta em que o sujeito requer, de início, informações identitárias do outro, para decidir se quer ou não formar um relacionamento com ele. Um novo usuário, ainda não familiarizado com a linguagem do ambiente, não será capaz de constituir um ato comunicativo a partir dessa pergunta.

É preciso esclarecer ainda que Schutz não considera que a comunicação se restrinja à significação verbal. 0 autor observa também "as funções específicas dos movimentos corporais do outro, enquanto campo de expressão aberto à interpretação, como signos do pensamento do outro" (SCHUTZ, 1979, p. 203). 0 relacionamento, dessa forma, também se constitui pelo uso de signos corporais, sejam eles propositais (gestos convencionados, como balançar a cabeça em negação), expressivos (movimentos de exteriorização não intencional dos sentimentos) ou miméticos (que buscam representar algo, como na imitação de um animal). Nas interações do modo video, como, por exemplo, no caso do sexo virtual, notamos que a linguagem corporal pode ocupar, de fato, uma função central no ato comunicativo.

Contudo, até aqui, abordamos somente os casos dos modos text e video, nos quais dois usuários interagem mutuamente. No modo spy (question), há ainda a presença de um terceiro sujeito, que apenas observa a conversa. Temos, assim, um tipo distinto de "orientação para o tu", no qual o usuário está consciente da outra pessoa sem que ela esteja consciente dele. Segundo Schutz (1979, p. 182), em casos como esse, a orientação é indireta, pois deixa de configurar uma compreensão recíproca e passa a ser um processo unilateral, fundado na observação social. Nesse sentido, se por um lado o spy (question) não pode se considerado um relacionamento direto, embora mantenha algumas das características dos outros modos de interação do site, ele pode ser utilizado como uma ferramenta que possibilita a observação dos relacionamentos por fora deles, mais próximos, portanto, de sua forma pura. Dessa maneira, o Omegle oferece um outro modo experimentar o relacionamento, no qual o sujeito não desempenha o papel de ator, mas participa como uma espécie de audiência: o usuário do spy (question) não está interessado em jogar; ele quer apenas assistir o jogo.

\section{A constituição do sujeito "estranho"}

Como foi mencionado, o usuário do Omegle não pode escolher um nickname. Ele sequer pode utilizar o seu próprio nome como elemento de identificação. Ao iniciar um chat, o sujeito é imediatamente enquadrado com o pronome inglês you ("você", na versão em português do site), destacado na cor azul; o contrassujeito com que ele estabelece a interação, por sua vez, 
é quem recebe 0 adjetivo stranger (estranho), na cor vermelha. Ao partirmos da máxima de Émile Benveniste (1991, p. 286) de que "é na linguagem e pela linguagem que 0 homem se constitui como sujeito", percebemos que "você" e "estranho" não correspondem a autodesignações, e sim tratam-se de pessoas linguísticas criada pelo próprio site, numa opção estratégica de não nomear os sujeitos anônimos utilizando os pronomes pessoais "eu" e "tu". A escolha dos termos está relacionada, evidentemente, à funcionalidade do site e firma o papel de ambiente que ele desempenha nos relacionamentos: é o Omegle que coloca "você" para conversar com um "estranho". Desse modo, a designação de "estranho" equivale à categoria linguística de pessoa e foi criada pelo site em oposição ao pronome "você", de forma que a atribuição fosse resultante da alteridade: o "estranho" é sempre o outro. Como conclui Benveniste (1991, p. 286), "essa é a condição de diálogo é que é constitutiva da pessoa, pois implica em reciprocidade".

Mas a discussão da constituição do sujeito não se encerra na categoria da pessoa. Paul Ricoeur (1991) demarcou a intenção filosófica de recolocar a pergunta "quem?" e problematizar a posição do sujeito que se autodesigna um "eu". Por essa via de pensamento, deixa-se de trabalhar num plano apenas linguístico e se passa a problematizar pelo viés da identidade. No nosso caso, perguntamos: quem é o sujeito que recebe a designação de "estranho"? Para responder a um problema dessa natureza, Ricoeur propõe uma dialética entre dois conceitos de identidade: mesmidade e ipseidade.

A mesmidade (ou identidade-idem) confunde a questão "quem?" com a questão "o quê?" e responde o problema na construção de um núcleo imutável do sujeito, que garante a sua permanência no tempo. Essa construção tem uma componente qualitativa, referente às marcas que nos permitem distinguir (e, do mesmo modo, assemelhar) os sujeitos, e também uma componente quantitativa, no sentido de que toda identidade é composta de forma numérica, através de repetições. Segundo Ricoeur (1991, p. 141), "essas duas componentes são irredutíveis uma à outra" e formam o substrato de identificação do sujeito: 0 reconhecimento nada mais é do que a percepção de qualidades observadas em um determinado número de ocorrências.

Já a ipseidade (ou identidade-ipse) coloca 0 próprio "eu" à frente da pergunta "quem?" e a resposta do problema se dá por uma construção narrativa. Esse conceito considera a dimensão temporal como um fator de mudança: 0 fato de que sujeito se modifica e que ele próprio se torna um outro. Trata-se, desse modo, de um tipo diferente de permanência no tempo, que não é "redutível à determinação de um substrato" (RICOEUR, 1991, p. 143). Ao sustentar a ipseidade na teoria da narrativa, Ricoeur propõe que a sua construção se dá a partir de três componentes: 0 personagem, a ação e a intriga. Em suma, a ideia do autor é que a intriga retira o personagem do seu estado 
de equilíbrio e o motiva a voltar-se à continuidade ininterrupta da sua vida, numa reflexão sobre as suas próprias ações. Ricoeur (1991, p. 170-171) descreve com precisão, no trecho seguinte, como esses elementos se articulam na composição da identidade narrativa:

0 passo decisivo em direção de uma concepção narrativa da identidade pessoal é dado quando passamos da ação ao personagem. É personagem aquele que faz a ação na narrativa. A categoria do personagem é, portanto, ela também, uma categoria narrativa, e seu papel na narração depende da própria inteligência narrativa que a intriga a si mesma. A questão é saber 0 que a categoria narrativa do personagem traz a discussão da identidade pessoal. A tese aqui sustentada será que a identidade do personagem compreende-se por transferência para ele da operação de intriga primeiramente aplicada à ação relatada; 0 personagem, diremos, é ele a própria intriga.

Pensada de acordo com a dialética de Ricoeur, podemos notar que a constituição do sujeito "estranho" no ambiente do Omegle está associada, num primeiro momento, a um processo de dissolução do polo da mesmidade, tanto em relação a sua componente qualitativa como quantitativa.

Como 0 site não permite a construção de perfis, 0 uso de avatares, de fotos etc., o sujeito é destituído de todas as qualidades e marcas distintivas que permitiriam a sua identificação. 0 único componente de identidade qualitativa possível se dá no modo video, com a troca de imagens via webcam: 0 "estranho" passa a ter um corpo. Ainda assim, mesmo nesse modo de interação, boa parte dos sujeitos opta por não revelar o rosto, que é, em tese, 0 elemento que agrega os traços corporais fundamentais de identificação. É bastante comum encontrarmos a opção pelo anonimato mesmo no modo video a partir do uso de máscaras ou de enquadramentos abaixo do pescoço. Em sua maioria, a ocultação do rosto está associada à nudez, numa estratégia de autopreservação.

A mesmidade também não é construída no Omegle pela componente quantitativa, à medida que 0 sistema randômico impossibilita uma repetição ordenada dos pares de conversação. Se esses pares se repetissem sistematicamente seria possível reconhecer os sujeitos em certo nível, por meio da repetição de determinadas expressões verbais, reações, motivações, pensamentos, ou seja, pelo desenvolvimento da compreensão subjetiva mútua. Foi baseado nesse argumento que consideramos anteriormente a escolha do idioma um risco para a manutenção do anonimato: ao dividir os usuários em grupos e, consequentemente, gerar repetições nos pares de conversa, a identidade-idem pode ser reconstruída por sua componente numérica.

Se por um lado a constituição do "estranho" depende da dissolução da identidade qualitativa e numérica, ao estabelecer uma conversa, o sujeito tem a possibilidade de narrar sua vida para 0 outro e reconstruir sua identidade pela via da ipseidade. Na nossa navegação pelo site, notamos que boa parte das conversas que se prolongam tem as narrativas de vida como conteúdo principal. Esse sujeito encontra no Omegle um ambiente ideal para assumir o papel de personagem e 
narrar as ações decorrentes da intriga que 0 motiva, em desabafos e confissões que buscam 0 aconselhamento do outro. Isso ocorre porque a ipseidade se aproveita da dissolução da mesmidade. Em outras palavras, a intriga se apoia no anonimato. Muitas dessas identidades narrativas são construídas no site, pois os sujeitos optam por ocultá-las nos ambientes de comunicação em que eles são identificados. Esse sigilo garantido à narrativa do outro, aproxima, de certo modo, a interação do Omegle a outras formas de sociabilidade, como, por exemplo, a terapia psicanalítica e a confissão católica.

Assim, pensado segundo a dialética da identidade de Ricoeur, o sujeito é destituído da sua mesmidade para receber a designação de "estranho". Nada impede, porém, que ele mesmo construa uma identidade-ipse, que não age em prol de seu reconhecimento, e sim é formada no interior de um relacionamento, através de narrativas de si.

\section{Considerações finais: a forma da interação}

Ao observarmos as interações entre estranhos do Omegle como resultantes do fenômeno da sociabilidade, podemos notar que, de fato, elas são voltadas a múltiplos propósitos. Citamos alguns no decorrer do artigo: a simples conversa, o sexo virtual, a aprendizagem autônoma de língua, a observação social, a narrativa de vida. Ao seguirmos o movimento proposto por Simmel (1983), convergimos, então, os dados observados nessas interações de diferentes conteúdos para apreender aquilo que elas têm em comum: sua forma. A reflexão acerca das duas características diferenciais do site (a randomização e 0 anonimato) nos encaminhou a compreensão dos elementos fundamentais desse jogo social.

A dimensão lúdica do Omegle se caracteriza, em primeiro lugar, pelo equilíbrio. A função do anonimato é dissipar as diferenças entre os sujeitos. Além disso, eles desempenham papéis iguais no jogo, com acesso às mesmas ferramentas de interação, com exceção do modo spy (question), que implica em uma forma diferente de participação. Eles podem ainda, como foi mencionado, definir o momento de entrar e sair de um relacionamento, tendo, assim, uma autonomia nas suas escolhas.

0 modo video ilustra bem a relação entre a autonomia dos participantes e 0 equilíbrio do jogo. Ao iniciar uma interação por vídeo, o usuário não é obrigado a conceder o seu sinal de webcam. Com isso, por um lado, a autonomia do sujeito permite um desequilíbrio: alguém pode receber a imagem do outro sem ter que enviar a sua. Por outro lado, testamos esse tipo de participação e logo percebemos a dificuldade de estabelecer um relacionamento nele. Pois, quem envia o seu sinal de vídeo não aceita 0 desequilíbrio e finaliza imediatamente a interação. Desse modo, o Omegle é um 
jogo social equilibrado e são os próprios participantes, no exercício da autonomia, que prezam pela igualdade.

0 segundo elemento que compõe o jogo é a efemeridade. Os relacionamentos do Omegle não têm passado e futuro, sendo fincados exclusivamente no presente, à medida que 0 sistema não permite ao participante a escolha do seu par de conversação. Os sujeitos, se desejarem, podem até dar continuidade à interação se trocarem informações que encaminhem a encontros posteriores, que nunca ocorrerão no Omegle, e sim em outros ambientes. Além disso, a formação de um relacionamento depende, como foi apontado anteriormente, do compartilhamento mínimo de linguagens e motivações entre os usuários. Mesmo com a disponibilização de ferramentas que conduzem o sistema randômico segundo essas variáveis, como o common interests, 0 facebook likes e a seleção do idioma, a maioria dos relacionamentos tem curta duração e pode levar algum tempo até que se encontre um parceiro de conversa duradouro. Nesse sentido, a efemeridade encaminha o participante a um trânsito contínuo de relacionamento em relacionamento, fazendo com que 0 jogo demande certa paciência.

Por outro lado, esse trânsito randômico confere ao jogo o elemento do suspense. 0 participante vive a expectativa de não saber com quem vai interagir em seguida e, motivado por esse sentimento, permanece jogando. Por isso que se convencionou no Omegle a prática de iniciar as interações com a pergunta "asl?", que congrega três informações referentes à mesmidade: ela reflete 0 interesse imediato do participante na identidade do outro, na ansiedade de decidir se deve interromper o fluxo de navegação e constituir um relacionamento, ou se deve permanecer em trânsito. Essa é a escolha central do jogo.

Uma vez que os usuários optem por investir em um relacionamento, eles devem se dedicar ao máximo a ele, pois a interação no Omegle é moldada em um circuito dinâmico de ação e reação. Se um sujeito, por exemplo, faz uma pergunta e não recebe uma resposta imediata, ele logo desiste e parte para o relacionamento seguinte. Nessa via, outro elemento que compõe o jogo é o dinamismo. Diferente do que ocorre em outros sites de chat, a participação no Omegle dificulta o desempenho de atividades simultâneas, sejam elas on-line ou off-line, pois o jogo exige concentração.

Desse modo, é a articulação entre 0 equilíbrio dos participantes, a efemeridade dos relacionamentos, 0 suspense da navegação randômica e 0 dinamismo das ações que dá forma à interação entre estranhos do Omegle. É evidente que alterações no funcionamento do site - que notamos serem frequentes -, podem reconfigurar algum desses elementos, o que implicaria em um risco à manutenção do jogo, tal como o descrevemos.

\section{Referências}

BENVENISTE, Émile. Problemas de linguística geral I. Campinas, SP: Pontes, 1991. 
PRIM0, Alex. Interação mútua e reativa: uma proposta de estudo. Revista da Famecos, Porto Alegre, n. 12, p. $81-92,2000$.

RICOEUR, Paul. 0 si-mesmo como um outro.

Campinas, SP: Papirus, 1991.

SCHUTZ, Alfred. Fenomenologia e relações sociais: textos escolhidos de Alfred Schutz. Rio de Janeiro:

Zahar, 1979.

SIBILIA, Paula. 0 show do eu: a intimidade como espetáculo. Rio de Janeiro: Nova Fronteira, 2008.

SIMMEL, Georg. Sociologia. São Paulo: Editora Ática, 1983.

SILVA, Jesiel Soares. Tecendo novas possibilidades na rede: 0 chat randômico como alternativa de interaçãa e aprendizagem autônoma de língua. In: ENCONTRO ESTADUAL DE DIDÁTICA E PRÁTICAS DE ENSINO, 4., 2011. Goiânia. Anais... Goiânia: Centro de Estudos e

Pesquisa em Didática, 2011. 


\section{Interaction with strangers on Omegle.com: sociability, relationship and identity}

\section{Abstract}

In light of the method proposed by Simmel, centered on the concept of sociability, in this article we investigate the ludic dimension of the conversational site 0megle.com, aiming to apprehend the form of their interactions. For this, we problematize the two differential characteristics of the site. First, based on the social phenomenology of Schutz, we discuss the formation of relationships through the use of a random system. Secondly, based on the dialectic of identity of Ricoeur, we reflect how the site constitutes an anonymous subject, designated as "stranger." In conclusion, we believe that the social game played on Omegle is characterized by equilibrium, dynamism and ephemerality, being used for many different purposes, such as simple talk, virtual sex, autonomous learning and social observation.

\section{Keywords}

Social interaction. Omegle. Sociability.

Relationship. Identity.

\section{La interacción entre extraños en Omegle.com: sociabilidad, relaciones e identidad}

\section{Resumen}

A la luz del método propuesto por Simmel, centrado en el concepto de sociabilidad, investigamos en este artículo la dimensión lúdica del sitio web de conversación Omegle.com, con el objetivo de entender la forma de sus interacciones. Para esto, cuestionamos las dos características diferenciales del sitio. Primeramente, basados en la fenomenológica social de Schutz, discutimos la formación de relaciones a través del uso de un sistema aleatoria. En segundo lugar, fundados en la dialéctica de la identidad de Ricoeur, reflexionamos de como el sitio web constituye un sujeto anónimo, designado de "extraño". Como conclusión, entendemos que el juego social practicado en 0megle se caracteriza por el equilibrio, dinamismo y ser efímero, siendo utilizado para los más diferentes propósitos, como la simple conversación, el sexo virtual, el aprendizaje autónomo y la observación social.

\section{Palabras-Clave}

Interacción social. Omegle. Sociabilidad.

Relaciones. Identidad. 


\section{Expediente}

A revista E-Compós é a publicação científica em formato eletrônico da Associação Nacional dos Programas de Pós-Graduação em Comunicação (Compós). Lançada em 2004, tem como principal finalidade difundir a produção acadêmica de pesquisadores da área de Comunicação, inseridos em instituições do Brasil e do exterior.

\section{E-COMPÓS I www.e-compos.org.br I E-ISSN 1808-2599}

Revista da Associação Nacional dos Programas

de Pós-Graduação em Comunicacão.

Brasília, v.16, n.3, set./dez. 2013

A identificação das edições, a partir de 2008

passa a ser volume anual com três números.

\section{CONSELHO EDITORIAL}

Afonso Albuquerque, Universidade Federal Fluminense, Brasil Alberto Carlos Augusto Klein, Universidade Estadual de Londrina, Brasil Alex Fernando Teixeira Primo, Universidade Federal do Rio Grande do Sul, Brasil Ana Carolina Damboriarena Escosteguy, Pontifícia Universidade Católica do Rio Grande do Sul, Brasi

Ana Gruszynski, Universidade Federal do Rio Grande do Sul, Brasil Ana Silvia Lopes Davi Médola, Universidade Estadual Paulista, Brasil André Luiz Martins Lemos, Universidade Federal da Bahia, Brasil Ângela Freire Prysthon, Universidade Federal de Pernambuco, Brasil Antônio Fausto Neto, Universidade do Vale do Rio dos Sinos, Brasil Antonio Carlos Hohlfeldt, Pontifícia Universidade Católica do Rio Grande do Sul, Brasil Antonio Roberto Chiachiri Filho, Faculdade Cásper Líbero, Brasil Arlindo Ribeiro Machado, Universidade de São Paulo, Brasil Arthur Autran Franco de Sá Neto, Universidade Federal de São Carlos, Brasil Benjamim Picado, Universidade Federal Fluminense, Brasil César Geraldo Guimarães, Universidade Federal de Minas Gerais, Brasil Cristiane Freitas Gutfreind, Pontifícia Universidade Católica do Rio Grande do Sul, Brasil Denilson Lopes, Universidade Federal do Rio de Janeiro, Brasi Denize Correa Araujo, Universidade Tuiuti do Paraná, Brasi Edilson Cazeloto, Universidade Paulista , Brasil

Eduardo Peñuela Cañizal, Universidade Paulista, Brasil

Eduardo Vicente, Universidade de São Paulo, Brasi

Eneus Trindade, Universidade de São Paulo, Brasi

Erick Felinto de Oliveira, Universidade do Estado do Rio de Janeiro, Brasi

Florence Dravet, Universidade Católica de Brasília, Brasi

Francisco Eduardo Menezes Martins, Universidade Tuiuti do Paraná, Brasil

Gelson Santana, Universidade Anhembi/Morumbi, Brasi

Gilson Vieira Monteiro, Universidade Federal do Amazonas, Brasil

Gislene da Silva, Universidade Federal de Santa Catarina, Brasil

Guillermo Orozco Gómez, Universidad de Guadalajara

Gustavo Daudt Fischer, Universidade do Vale do Rio dos Sinos, Brasil Hector 0spina, Universidad de Manizales, Colômbia

Herom Vargas, Universidade Municipal de São Caetano do Sul, Brasi leda Tucherman, Universidade Federal do Rio de Janeiro, Brasil

Inês Vitorino, Universidade Federal do Ceará, Brasil

Janice Caiafa, Universidade Federal do Rio de Janeiro, Brasil

Jay David Bolter, Georgia Institute of Technology

Jeder Silveira Janotti Junior, Universidade Federal de Pernambuco, Brasi João Freire Filho, Universidade Federal do Rio de Janeiro, Brasil
John DH Downing, University of Texas at Austin, Estados Unidos

José Afonso da Silva Junior, Universidade Federal de Pernambuco, Brasi José Carlos Rodrigues, Pontifícia Universidade Católica do Rio de Janeiro, Brasil José Luiz Aidar Prado, Pontifícia Universidade Católica de São Paulo, Brasil José Luiz Warren Jardim Gomes Braga, Universidade do Vale do Rio dos Sinos, Brasil Juremir Machado da Silva, Pontifícia Universidade Católica do Rio Grande do Sul, Brasil Laan Mendes Barros, Universidade Metodista de São Paulo, Brasi Lance Strate, Fordham University, USA, Estados Unidos Lorraine Leu, University of Bristol, Grã-Bretanha Lucia Leão, Pontifícia Universidade Católica de São Paulo, Brasil Luciana Panke, Universidade Federal do Paraná, Brasil Luiz Claudio Martino, Universidade de Brasília, Brasi Malena Segura Contrera, Universidade Paulista, Brasil

Márcio de Vasconcellos Serelle, Pontifícia Universidade Católica de Minas Gerais, Brasil Maria Aparecida Baccega, Universidade de São Paulo e Escola Superior de Propaganda e Marketing, Brasi

Maria das Graças Pinto Coelho, Universidade Federal do Rio Grande do Norte, Brasil Maria Immacolata Vassallo de Lopes, Universidade de São Paulo, Brasil Maria Luiza Martins de Mendonça, Universidade Federal de Goiás, Brasil Mauro de Souza Ventura, Universidade Estadual Paulista, Brasil

Mauro Pereira Porto, Tulane University, Estados Unidos

Nilda Aparecida Jacks, Universidade Federal do Rio Grande do Sul, Brasi Paulo Roberto Gibaldi Vaz, Universidade Federal do Rio de Janeiro, Brasi Potiguara Mendes Silveira Jr, Universidade Federal de Juiz de Fora, Brasi Renato Cordeiro Gomes, Pontifícia Universidade Católica do Rio de Janeiro, Brasil Robert K Logan, University of Toronto, Canadá Ronaldo George Helal, Universidade do Estado do Rio de Janeiro, Brasil Rosana de Lima Soares, Universidade de São Paulo, Brasi Rose Melo Rocha, Escola Superior de Propaganda e Marketing, Brasil Rossana Reguillo, Instituto de Estudos Superiores do Ocidente, Mexico Rousiley Celi Moreira Maia, Universidade Federal de Minas Gerais, Brasi Sebastião Carlos de Morais Squirra, Universidade Metodista de São Paulo, Brasil Sebastião Guilherme Albano da Costa, Universidade Federal do Rio Grande do Norte, Brasil

Simone Maria Andrade Pereira de Sá, Universidade Federal Fluminense, Brasi Tiago Quiroga Fausto Neto, Universidade de Brasília, Brasil Suzete Venturelli, Universidade de Brasília, Brasil Valerio Fuenzalida Fernández, Puc-Chile, Chile

Veneza Mayora Ronsini, Universidade Federal de Santa Maria, Brasi Vera Regina Veiga França, Universidade Federal de Minas Gerais, Brasi

COMISSÃO EDITORIAL

Adriana Braga I Pontifícia Universidade Católica do Rio de Janeiro, Brasi

CONSULTORES AD HOC

Adriana Amaral, Universidade do Vale do Rio dos Sinos, Brasil

Alexandre Rocha da Silva, Universidade Federal do Rio Grande do Sul, Brasi

Arthur Ituassu, Pontifícia Universidade Católica do Rio de Janeiro, Brasil

Bruno Souza Leal, Universidade Federal de Minas Gerais, Brasil

Elizabeth Bastos Duarte, Universidade Federal de Santa Maria, Brasil

Francisco Paulo Jamil Marques, Universidade Federal do Ceará, Brasi

Maurício Lissovsky, Universidade Federal do Rio de Janeiro, Brasi

Suzana Kilpp, Universidade do Vale do Rio dos Sinos, Brasil

Vander Casaqui, Escola Superior de Propaganda e Marketing, Brasil

EDIÇÃO DE TEXTO E RESUMOS I Susane Barros

SECRETÁRIA EXECUTIVA I Juliana Depiné

EDITORAÇÃO ELETRÔNICA I Roka Estúdio

TRADUÇÃ̃o I Sieni Campos
COMPÓS I www.compos.org.br

Associação Nacional dos Programas de Pós-Graduação em Comunicação

Presidente

Eduardo Morettin

Universidade de São Paulo, Brasil

eduardomorettin@usp.br

Vice-presidente

Inês Vitorino

ines@ufc.br

Secretária-Geral

Gislene da Silva

Universidade Federal de Santa Catarina, Brasi

gislenedasilva@gmail.com
Universidade Federal do Ceará, Brasil 